\title{
Global mapping of research trends on antibacterial activity of green silver nanoparticles
}

\author{
Kunle Okaiyeto ${ }^{1}$, Idowu Olaposi Omotuyi ${ }^{2}$ \& Oluwafemi Omoniyi Oguntibeju ${ }^{1^{\star}}$ \\ ${ }^{1}$ Phytomedicine and Phytochemistry Group, Department of Biomedical Sciences, Faculty of Health and Wellness Sciences, Cape Peninsula University of \\ Technology, Bellville 7535, South Africa \\ ${ }^{2}$ Department of Biochemistry, Adekunle Ajasin University, Akungba-Akoko, Ondo State, Nigeria \\ *Email: oguntibejuo@cput.ac.za
}

OPEN ACCESS

\section{ARTICLE HISTORY}

Received: 11 June 2021

Accepted: 29 October 2021

Available online

Version 1.0 (Early Access): 10 December 2021

Version 2.0:01 January 2022

\section{Check for updates}

\section{Additional information}

Peer review: Publisher thanks Sectional Editor and the other anonymous reviewers for their contribution to the peer review of this work.

Reprints \& permissions information is available at https://horizonepublishing.com/ journals/index.php/PST/open_access_policy

Publisher's Note: Horizon e-Publishing Group remains neutral with regard to jurisdictional claims in published maps and institutional affiliations.

Indexing: Plant Science Today, published by Horizon e-Publishing Group, is covered by Scopus, Web of Science, BIOSIS Previews, Clarivate Analytics, etc. See https:// horizonepublishing.com/journals/index.php/ PST/indexing_abstracting

Copyright: ( $)$ The Author(s). This is an openaccess article distributed under the terms of the Creative Commons Attribution License, which permits unrestricted use, distribution and reproduction in any medium, provided the original author and source are credited (https://creativecommons.org/licenses/ by/4.0/)

\section{CITE THIS ARTICLE}

Okaiyeto K, Omotuyi I O, Oguntibeju 0 O. Global mapping of research trends on antibacterial activity of green silver nanoparticles. Plant Science Today. 2022;9(1):105-118. https://doi.org/10.14719/pst.1316

\begin{abstract}
Over the years, the quest for antibacterial agents from green nanoparticles has attracted great attention due to the global rise in the prevalence of multi-drug resistant bacteria. Although several studies on the antibacterial activity of plant-mediated silver nanoparticles have been documented, no bibliometric studies on the subject have been reported to date. As a result, the present study aimed to assess the global research trends on the antibacterial activity of green silver nanoparticles from 2000 to 2020. In the present study, we explored Science Citation Index Expanded (SCIE) to extract research articles written in English on the subject within the specified period. Two hundred and sixty-nine (269) eligible research articles were included in the bibliometric analysis and R-package "bibliometrix" was used to analyse the documents for annual scientific publications, authors' impact, most relevant institutions, countries productivity, frequent words, co-occurrence network, co-citation network and authors/institutions/countries collaboration networks. Based on the analysis, the top three (3) authors, journals, institutions and countries were Kumar V $(n=5)$, Zangeneh MM $(n=5)$ and Oh BT $(n=4)$; King Saud University, Banaras Hindu University and Islamic Azad University; Journal of Cluster Science $(n=10)$, Applied Organometallic Chemistry $(n=8)$ and Microbial Pathogenesis $(n=8)$; India, Iran, and Korea. The study findings highlighted the gaps in a research collaboration that negate productivity. Therefore, we are optimitic that this study would enlighten researchers in the field about the research lapses and the need for research collaboration in future studies.
\end{abstract}

\section{Keywords}

Bibliometric analysis, scientific productivity, green silver nanoparticles, antibacterial activity

\section{Introduction}

Metal nanoparticles are among the groups of nanomaterials that have been widely considered lately due to their exceptional physicochemical properties and various applications $(1,2)$. The uses of the nanomaterials cut across several fields (3). Nanomaterials are particles that are in nanoscale size (1 $100 \mathrm{~nm}$ ), and they are very small particles with enhanced catalytic, thermal conductivity, reactivity, chemical stability nonlinear optical performance due to their large surface area-to-volume ratio $(1,4)$. These salient characteristics have appealed to many researchers in the field to search for novel methods for their synthesis (5-7). Different physical and chemical methods such as hydrothermal method, physical-vapor deposition, electrochemical 
changes, laser ablation, microwave technique, flame pyrolysis, photochemical reduction, spray pyrolysis, solvothermal, chemical reduction, sol-gel methods are commonly employed for the preparation and stabilization of metallic nanoparticles (8-12). High energy and pressure are required for physical methods and these made them too expensive while the chemical methods involved the use of expensive and toxic chemicals and these adverse effects have restricted their usage (9, 13-15).

Green nanotechnology is an emerging area in nanoscience due to the demand for a novel and effective approach for their synthesis (16). Although, physical and chemical methods of synthesis of metal nanoparticles can produce small-sized and well-defined particles; however, the adverse effects associated with the use of these procedures have shifted the attention of researchers to the use of biological agents (17). These biological substrates are known to be innocuous, a propitious and promising alternative to conventional methods of synthesis $(18,19)$. Among these biological agents, the use of extracts of plant materials has been acknowledged as the simplest and fastest preference for metal nanoparticle synthesis $(20,21)$. Besides being simple, this method is efficient and offers good reproducibility. In phytofabricated nanoparticle synthesis, particle properties such as size and shape are easily manipulated by changing salt concentrations, the volume of extracts, temperature, $\mathrm{pH}$ and time of exposure (16). In addition, the low cytotoxic activity of the metals nanoparticles has enhanced their applicability in medicine $(22,23)$.

Silver nanoparticles are the most widely used nanomaterials for different industrial and medical applications $(24,25)$. They possessed numerous unique features including but not limited to optical, electrical, antimicrobial, diamagnetic and thermal properties and these make them valuable for different applications $(26,27)$. Several researchers have reported on the synthesis of silver nanoparticles with antibacterial activity in the literature. For example, Skimmia laureola (28), Rumex hymenosepalus (29), Myrtus communis (30), Parkia speciosa (31), Holoptelea integrifolia (32), Oedera genistifolia (33), Vitis labrusca (34) and Muntingia calabura (35) have been explored for green synthesis. To understand the level of research progress in this field, there is a need to carry out a bibliometric analysis to grasp the holistic research trends on the subject that can provide new perspectives for future research.

Bibliometric analysis is an important statistical tool that quantitatively evaluates the scientific contribution of an author, institution and country in a particular field over the years $(36,37)$. The bibliometric analysis offers a quantitative review of literature in any field of research based on the citation frequency of the published research $(38,39)$. It is a statistical gauge that can measure the influence of research outputs within a particular subject or research field that represents the research hot spots and trends (40). As highlighted in the report (41), bibliometric analyses decrease the intrinsic bias of narrative and systematic assessments. The thrust areas of the past research in a speciality can be identified by analyzing the most-cited work cur- rently and the information can then be used to channel future research (42). It was noted that "literature on bibliometric studies has expanded beyond the level of publication analysis and that many communities have yet to utilize them as a strategy for gathering information that could be useful in understanding the patterns and trends in their local science" (43). Bibliometric analysis has been explored on different subjects such as bioflocculant (44), diabetes (45), Moringa oleifera (46), HIV (47), Malaria (48), comorbidity of cancer and pain (49) etc.

Considering the proliferation of literature on the subject under study, it was most appropriate that we conducted a bibliographical review based on the available experimental bibliometric data to determine the most prominent research scholars, institutions, countries in the field (41). Therefore, in the present study, a bibliometric analysis of global research trends on the antibacterial activity of plant-mediated silver nanoparticles was evaluated to assess the research performance of authors, journals, institutions and countries. In addition, citations analysis and research collaboration networks were investigated as well as the frequent keywords used in the field to determine the future direction of the research. Therefore, the significance of this study is to integrate and provide an organized summary of the existing research by identifying the foundational studies to build knowledge, gain an understanding, and show the future direction in this research area.

\section{Materials and Methods}

\section{Data retrieval}

The Web of Science was explored to extract published research articles on the antibacterial activity of green silver nanoparticles. The search queries were ( ${ }^{*}$ green silver nanoparticles* AND *antibacterial $\left.{ }^{\star}\right)$ and we focused only on research articles published on the subject study especially those indexed in Science Citation Index-Expanded (SCIE). About 293 published articles on the subject were retrieved from the Web of Science (WoS) database from 2000 to 2020. WoS is among the oldest, reliable and comprehensive databases to retrieve published documents that could be used for bibliometric studies (50). From our search, we specialized in research articles written in English and we excluded some other documents such as early access or proceedings paper or book chapter, and we obtained 269 research articles. Subsequently, these articles were downloaded in plain files format and thereafter saved in a notepad before analyses.

\section{Data analysis}

The bibliometric analysis was carried out on the R-package bibliometrix (51). The tool is designed for quantitative research in scientometrics and bibliometrics and it provides several routines for analysis and supports all the crucial steps of a classical bibliometric workflow (41). Retrieved data in plain text was uploaded in Biblioshiny on Rstudio software (v.3.4.1) to analyse the annual scientific production, authors' impact, institutions and countries research 
outputs, funding agencies, relevant journals, most cited with 6796 references. The average years from the publicapapers, keywords, historical direct citation network, co- tion were 3.27, average citations per document and average citation network authors/institution/countries collabora- citations per year per document were found to be 26.47 and tion networks.

\section{Results and Discussion}

5.167 , respectively. We found that authors appearance to be 1320 , authors of single-authored documents and authors of multi-authored documents to be 7 and 1151, respectively. The author's collaboration in the research field

The research trends in antibacterial activity of green silver nanoparticles research were carried out in the present study and we explored WoS as a source of the information for the bibliometric analysis (52). Given the global recognition of English, we only focused on those research articles written in English and excluded others that were written in other languages (53). However, the Web of Science Core Collection is not designed for bibliometric studies, but it can be explored for finding literature (54). Therefore, it is important for researchers to use SCI-EXPANDED with the accurate bibliometric method (55). As highlighted, Web of Science was explored as a target database due to the fact it is one of the oldest databases to extract research publications for different analyses and it has citation metrics from 1945 to the present (56). SCl-Expanded is the most important database for an overview of scientific production (57).

In the present study, Table 1 depicts vital information about the research trends of research on green sil-

Table 1. Main information about Data.

\begin{tabular}{lc}
\hline Description & Results \\
\hline "Timespan" & $2010-2020$ \\
"Sources (journals)" & 135 \\
"Documents" & 269 \\
"Average years from publication" & 3.27 \\
"Average citations per documents" & 26.47 \\
"Average citations per year per doc" & 5.167 \\
"References" & 6796 \\
"Document types" & \\
"Article" & 269 \\
"Document contents" & \\
"Keywords plus (id)" & 513 \\
"Author's keywords (de)" & 710 \\
"Authors" & 4.91 \\
"Authors" & 4.39 \\
"Author appearances" & 1158 \\
"Authors of single-authored documents" & 1320 \\
"Authors of multi-authored documents" & 7.3 \\
\hline "Collaboration index" & \\
\hline
\end{tabular}

ver nanoparticles with antibacterial activity from 2000 to 2020. About 1158 authors wrote the 269 research articles extracted from SCl-Expanded. They comprise 710 keywords 
(Table 2 and Fig. 2). Both Kumar V and Zangeneh MM Krishnaraj C, Iravani S and Shameli K (Supplementary Fig. S1). crowned the list with 5 articles each followed by Oh BT, In terms of authors' impact, the h-index was used as an in-

Table 2. Most relevant authors on antibacterial activity of green silver nanoparticles.

\begin{tabular}{|c|c|c|c|c|c|c|c|c|c|c|}
\hline \multicolumn{4}{|c|}{ Top 20 productive authors } & \multicolumn{7}{|c|}{ Top 20 impactful authors } \\
\hline Authors & Articles & Authors-Frac & $\begin{array}{l}\text { Articles Fraction- } \\
\text { alized }\end{array}$ & Author & $\begin{array}{c}h \\
\text { index }\end{array}$ & $\underset{\text { index }}{g_{-}}$ & $\mathrm{m}_{\text {index }}$ & TC & NP & $\begin{array}{l}\text { PY } \\
\text { start }\end{array}$ \\
\hline Kumar V & 5 & Zangeneh MM & 1,8167 & Zangeneh MM & 3 & 3 & 1,5 & 82 & 3 & 2019 \\
\hline Zangeneh MM & 5 & Arunachalam J & 1,3333 & Zangeneh A & 2 & 2 & 1 & 56 & 2 & 2019 \\
\hline Oh BT & 4 & Patra JK & 1,3333 & Karishma S & 1 & 1 & 0,5 & 3 & 2 & 2019 \\
\hline Veisi H & 4 & Kathiravan V & 1,1667 & Raji P & 1 & 1 & 0,5 & 3 & 2 & 2019 \\
\hline Arokiyaraj S & 3 & Al-ogaidi IAZ & 1 & Samrot AV & 1 & 1 & 0,5 & 3 & 2 & 2019 \\
\hline Arunachalam J & 3 & Chumpol J & 1 & Aadil KR & 1 & 1 & 0,5 & 5 & 1 & 2019 \\
\hline Bhatti TM & 3 & Mehata MS & 1 & Ahmad R & 1 & 1 & 0,5 & 3 & 1 & 2019 \\
\hline Cho M & 3 & Oda AM & 1 & Ahmed N & 1 & 1 & 0,5 & 1 & 1 & 2019 \\
\hline Jafarizadeh-Malmiri H & 3 & Siri S & 1 & Al Farraj DA & 1 & 1 & 0,5 & 1 & 1 & 2019 \\
\hline Jalali SAH & 3 & Yilmaz BYB & 1 & Al Khulaifi MM & 1 & 1 & 0,5 & 1 & 1 & 2019 \\
\hline Khan M & 3 & Samrot AV & 0,9048 & An QL & 1 & 1 & 0,5 & 3 & 1 & 2019 \\
\hline Kim GD & 3 & Veisi H & 0,8667 & Anand Mav & 1 & 1 & 0,5 & 2 & 1 & 2019 \\
\hline Lee SM & 3 & Kumar V & 0,8345 & Araujo MC & 1 & 1 & 0,5 & 14 & 1 & 2019 \\
\hline Mandal AK & 3 & Kora AJ & 0,8333 & Arulmozhi M & 1 & 1 & 0,5 & 7 & 1 & 2019 \\
\hline Mehmood A & 3 & Singh $\mathrm{H}$ & 0,8333 & Aulla SM & 1 & 1 & 0,5 & 1 & 1 & 2019 \\
\hline Murtaza G & 3 & $\mathrm{Du} \mathrm{J}$ & 0,8095 & Azeem M & 1 & 1 & 0,5 & 3 & 1 & 2019 \\
\hline Pandian K & 3 & Jalali SAH & 0,7833 & Bahabadi SE & 1 & 1 & 0,5 & 17 & 1 & 2019 \\
\hline Park JH & 3 & Bhatti TM & 0,7 & Bai YH & 1 & 1 & 0,5 & 5 & 1 & 2019 \\
\hline
\end{tabular}

TC- total citations, NP - number of publication, , PY - publication year

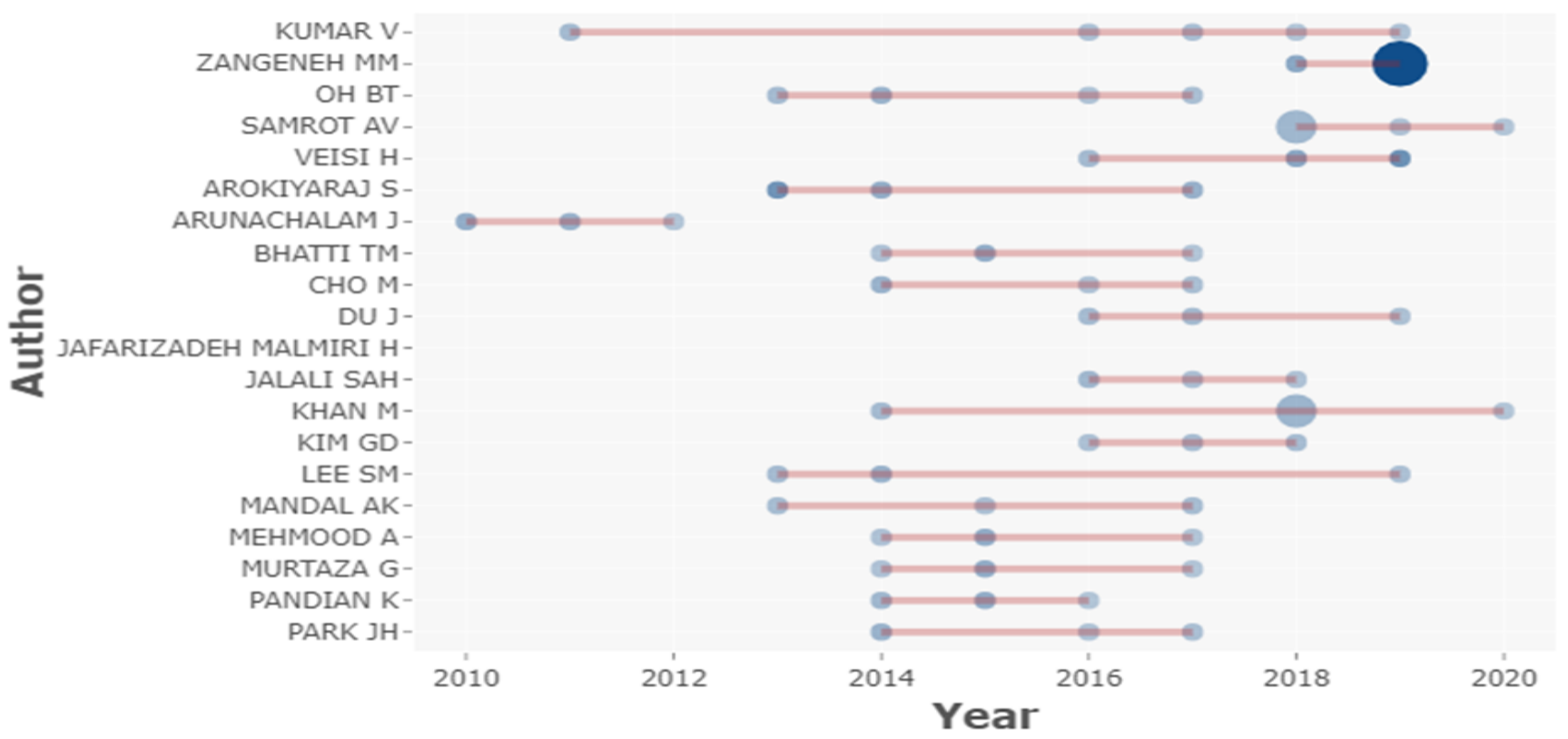

Fig. 2. Authors' productivity on antibacterial activity of green silver nanoparticles.

Samrot AV and Veisi $\mathrm{H}$ with 4 each. In terms of authors- dicator to measure the scientific impact of authors and the fraction, Zangeneh MM has articles fractionalized value of results are represented in Table 2 and the most impactful 1.8167 followed by Arunachalam J and Patra JK with author is Zangeneh MM (h-index of 3), total citation of 82 1.3333. In terms of the number of articles published on the since 2019, followed by Zangeneh A ( $h$-index of 2) with 56 subject, Kumar V $(n=5)$ was the most relevant author, but citations (Supplementary Table S1). According to the rethe most cited author was Shankar SS with 95 citations. The ports $(62,63)$, "perceptions of research productivity pat10 topmost cited references on the subject include Shankar terns of authors differ greatly, and the productivity pattern SS, Philip D, Sharma VK, Ahmed S, Rai M, Morones JR, Sondi I, of authors is not only subjective but also a function of an 
enabling scientific environment". Lotka's Law is often sis ( $n=8)$, Artificial Cells Nanomedicine and Biotechnology called "inverse square law", "indicating that there is an in- $(n=7)$, Colloids and Surfaces B-Biointerfaces. Only three (3) verse relationship between the number of publications and of the five (5) top journals focused on nanotechnology. Mithe number of authors producing these publications" (64). crobial Pathogenesis specializes in biological subjects and Connecting this law to our findings in the present study, we Colloids and Surfaces B-Biointerfaces is a general journal observed that when the number of documents was 1 , the with a wide scope of subjects. Journal of Cluster Science (hnumber of authors were 1034 and the proportion of the index 39) is a springer journal with an impact factor of 2.125 authors was 0.893 (Supplementary Table S2). As the num- (2018), active in production since 1990 and is a Chemistry ber increases to 5, the number of authors decreased to 2 discipline which fits into the subject of study and the jourand the proportion of authors was reduced to 0.002. In nal is devoted to publishing research on nanoparticles and terms of the authors' productivity over the year, Arokiyaraj this justifies why is the most relevant journey in the study. $S$ had total citations of 237 and a total citation per year of Applied Organometallic Chemistry is a Wiley Online Library 29625 in 2013 followed by Arunachalam J with 155 total that has an impact factor of 3.259, 17/71 (Chemistry, Apcitations and total citations per year of 14,091 in 2010 plied) 10/45 (Chemistry, Inorganic \& Nuclear). One critical (Supplementary Table S3). As reported (65), "the rate of factor that influences journal productivity is ranking in the citation may not reveal a researcher or nation's publishing field (67).

efficiency, because the larger the number of articles used for evaluation, the greater the influence of a few frequently cited articles". Consequently, as put forward "false quality metrics could result from self-citations, citation outside WoS, citation or articles published in predatory journals and inaccurate citations" (66).

\section{Most relevant journals and subject categories}

The results depicted in Table 3 show the most relevant journals on the subject. The top five (5) journals on the subject study included Journal of Cluster Science $(n=10)$, Applied Organometallic Chemistry $(n=8)$ and Microbial Pathogene-

Citation analysis involves calculating the number of times other researchers cite an article to gauge the impact of a publication or author. Papers published early gain more citations than those published in the recent time no matter the quality of the content and this means that it is improper to compare citations of papers published two decades ago with those published like a year ago. Hence, the impact of published articles is assessed after at least after 5 years of publication. As highlighted, an increase in the age of publication positively influenced the citation frequency (68). Hirsch announced the h-index in 2005 and subsequently, it became a very popular bibliometric meas-

Table 3. 20 most relevant journals on antibacterial activity of green silver nanoparticles.

\begin{tabular}{|c|c|c|c|c|c|c|}
\hline \multicolumn{3}{|l|}{ Most Relevant journals } & \multicolumn{4}{|c|}{20 most global cited documents } \\
\hline Sources & $\begin{array}{c}\text { Number } \\
\text { of arti- } \\
\text { cles }\end{array}$ & Sources & Citation & Paper & TC & $\begin{array}{l}\text { TC per } \\
\text { year }\end{array}$ \\
\hline Journal of Cluster Science & 10 & Colloid Surface B & 489 & Prakash P, 2013, Colloid Surface B & 237 & $\begin{array}{l}29,625 \\
29,625\end{array}$ \\
\hline Applied Organometallic Chemistry & 8 & Spectrochim Acta A & 307 & Jagtap UB, 2013, Ind Crop Prod & 194 & 24,25 \\
\hline Microbial Pathogenesis & 8 & Mater Lett & 209 & Khalil MMH, 2014, Arab J Chem & 192 & 27,429 \\
\hline Artificial Cells Nanomedicine and Biotechnology & 7 & J Colloid Interf Sci & 193 & Dhand V, 2016, Mat Sci Eng C-Mater & 173 & 34,6 \\
\hline Colloids and Surfaces B-Biointerfaces & 7 & Colloid Surface A & 191 & Saxena A, 2012, Mater Lett & 172 & 19,111 \\
\hline Journal of Photochemistry and Photobiology B-Biology & 7 & Nanotechnology & 167 & Sun Q, 2014, Colloid Surface A & 164 & 23,429 \\
\hline Materials Letters & 7 & Langmuir & 157 & Kora AJ, 2010, Carbohyd Polym & 155 & 14,091 \\
\hline $\begin{array}{l}\text { Spectrochimica Acta Part A-Molecular and Biomolecular } \\
\text { Spectroscopy }\end{array}$ & 7 & Int J Nanomed & 144 & Zargar M, 2011, Molecules & 150 & 15 \\
\hline Bionanoscience & 6 & $\begin{array}{l}\text { Nanomed Nano- } \\
\text { technol }\end{array}$ & 142 & Ravindra S, 2010, Colloid Surface A & 146 & 13,273 \\
\hline $\begin{array}{l}\text { Materials Science \& Engineering C-Materials for Biologi- } \\
\text { cal Applications }\end{array}$ & 6 & Ind Crop Prod & 132 & Hebeish A, 2011, Carbohyd Polym & 142 & 14,2 \\
\hline RSC Advances & 6 & J Nanopart Res & 131 & Anandalakshmi K, 2016, Appl Nanosci & 140 & 28 \\
\hline Applied Nanoscience & 5 & Carbohyd Polym & 127 & Reddy NJ, 2014, Mat Sci Eng C-Mater & 140 & 20 \\
\hline Bioprocess and Biosystems Engineering & 5 & $\begin{array}{l}\text { Dig J Nanomater } \\
\text { Bios }\end{array}$ & 121 & Dinesh D, 2015, Parasitol Res & 136 & 22,667 \\
\hline Carbohydrate Polymers & 5 & Mat Sci Eng C Mater & 117 & Shameli K, 2012, Chem Cent J & 132 & 14,667 \\
\hline IET Nanobiotechnology & 5 & Appl Nanosci & 107 & Venkatpurwar V, 2011, Mater Lett & 115 & 11,5 \\
\hline
\end{tabular}


Research on Chemical Intermediates

Arabian Journal of Chemistry

International Journal of Biological Macromolecules

Journal of Nanoscience and Nanotechnology
5 J Photoch hotobio B

4 J Am Chem Soc

4 Green Chem

4 RSC Adv
97

94

86

86
Rastogi L, 2011, Mater Chem Phys

114

Arokiyaraj S, 2014, Int J Nanomed 97

Das J, 2013, Spectrochim Acta A

Mariselvam R, 2014, Spectrochim Acta A
11,4

13,857

11,375

90

12,857 ure (69). According to one report, " $\mathrm{H}$-index is one specific method using citation analysis to determine an individual impact" (70). An individual's h-index usually vary in different databases and this could be to the fact that databases index different journals and cover different years. For instance, Scopus only have records of published papers from 1996 or later, while the Web of Science calculates an hindex using all years that an institution has subscribed to it.

The 269 research articles on the subject were distributed in 25 Web of Science subject categories (Supplementary Table S4). A total of 54 articles were published by Chemistry Multidisciplinary followed by Materials Science Multidisciplinary $(n=39)$, Nanoscience Nanotechnology $(n=39)$, Materials Science Biomaterials ( $n=31)$, Biotechnology Applied Microbiology ( $n=29)$, Chemistry Inorganic Nuclear $(n=21)$, Chemistry Applied $(n=19)$, Chemistry Physical ( $n=19)$, Engineering Chemical ( $n=19)$, Biochemistry Molecular Biology (18). This points out a big issue that comprises a huge separation between journals related to specific sectors and those that are more general. As underlined by relevant scholars, industry-specific and empirical papers should foster theoretical and general concepts in the field. It is also because authors who write in general journals often neglect reading articles in more specific but likewise important top journals, even if they are moresector specific. The most cited journal on the subject study in these 269 articles was Colloid Surface B with 489 citations followed by Spectrochim Acta A, Mater Lett, J Colloid Interf Sci, Colloid Surface A with 307 and 209, 193 and 191 respectively (Table 3 ).

According to Bradford's law, which states, "that Bradford's law was not useful for predicting the size of the literature on a subject from the number of articles appearing in core journals" (71). As described (72), "Bradford's Law of Scattering is a law of diminishing returns and scattering. Bradford formulated the law in 1948 and claimed that for a given subject area, there are a few very productive periodicals, a larger number of more moderate producers, and a still larger number of constantly diminishing productivity". Researchers have defined a subject area in lexical, semantic and subject scattering terms (73), and some argue that problems in defining "subject" may not matter, provided it is applied consistently (74). Relating Bradford's law to our findings in the present study, we found that out of the 20 top journals (Supplementary S5), the first thirteen journals belong to zone 1 , which implies that they are the most cited journals on the subject under study whereas, the remaining journals classified under zone 2 (middle third) have an average amount of citations (75). Bradford's model may reflect the highly interdisciplinary nature of the antibacterial activity of silver nanoparticle research.
According to one report (71), this law has been applied successfully to measure the literature of many subjects. The frequently cited articles may be assumed to have been more useful than publications that are rarely cited or not at all and be more useful and thus important in their own right (76). This means that the number of citations may be considered as a measure of the article's usefulness, impact, or influence on another research. The same perceptive can be used for aggregated levels of articles. This is the typical way of justifying the use of citations as a performance indicator. Recently, the connection between scholarly quality and citations has become more intricate as researchers have realized the need to increase their visibility. This has become urgent as research funding has become scarce and the competition for resources has sharpened. In addition, since the use of citation indicators as performance indicators, researchers know that their references may influence the careers of the researchers they cite (77). The trend analysis of the influence of age of publication on the citation density showed that certain topics after reaching maturity show a decrease in citation density (68). It has been described that the real impact of a publication can only be evaluated at least two decades after it has been published $(68,78)$. Nevertheless, it is remarkable that with the changing trends of how published work is reviewed, the accessibility of literature has increased multi folds, and

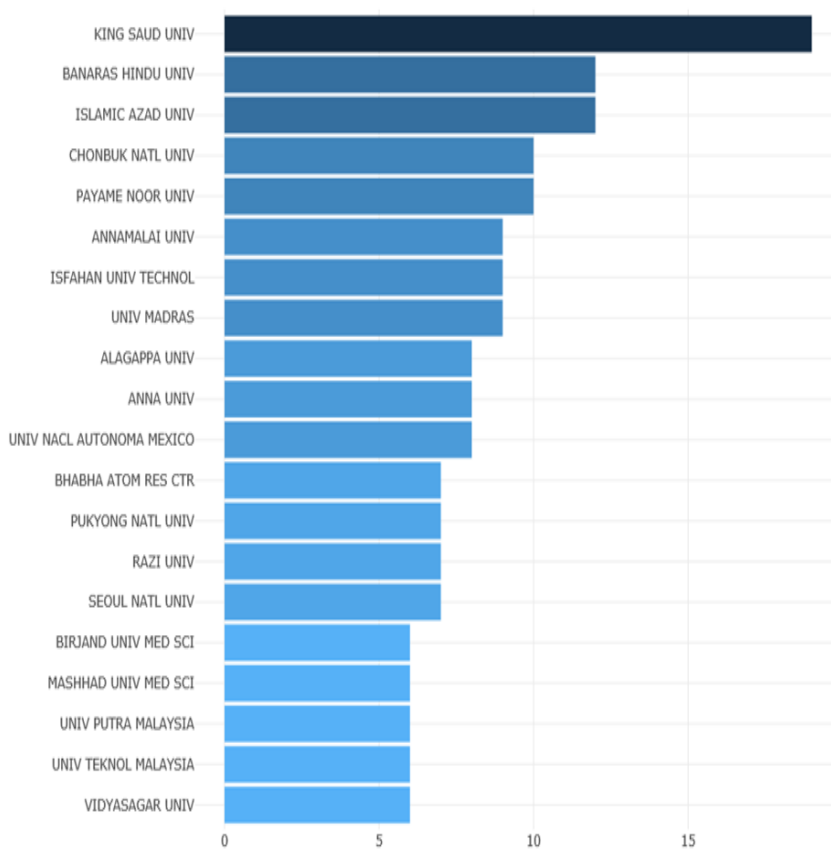

Fig. 3. Top 20 most relevant affiliation

research from around the world can be remotely reviewed without needing access to archives, libraries and published paper journals (68). 


\section{Most relevant affiliations}

Based on the distribution analysis of the relevant institutions on the subject, it would be stress-free to comprehend the scientific research capabilities of each institution and their global contribution in the field and perhaps, the outputs of the corresponding authors originating from such institutions. Fig. 3 depicts the top 20 institutions on the subject and we found that King Saud Univ top the group with 19 articles, followed by Banaras Hindu Univ (12), Islamic Azad Univ (12), Chonbuk Natl Univ (10), Payame Noor Univ (10), Annamalai Univ (9), Isfahan Univ Technol (9), Univ Madras (9), Alagappa Univ (8), Anna Univ (8), Univ Nacl Autonoma Mexico (8), Bhabha Atom Res Ctr (7), Pukyong Natl Univ (7), Razi Univ (7), Seoul Natl Univ (7), Birjand Univ Med Sci (6), Mashhad Univ Med Sci (6), Univ Putra Malaysia (6), Univ Teknol Malaysia (6), Vidyasagar Univ (6). From our results, it is surprising that none of the research-based centres made it to the top 20 . It could be seen that the universities dominated the field, and this could be possible since most of the researchers working at research centres are not keen on publication unlike the academics at the universities where publication is part of the criteria required for their academic promotion assessment. Secondly, in some countries such as South Africa, the amount of funding released by the government to each university is determined by their productivity, which includes the research outputs and number of postgraduates who graduated in a year. This approach promotes productivity, consequently the number of published articles. However, we are not sure whether funding in other countries is dependent on research productivity and how much of that affected research productivity among the top countries reported in this study.

\section{Countries productivity}

Based on the search queries, the top 20 most productive, most cited, and authors' countries are represented in Table 4. India is the most productive (270), most cited (3468), and top author's corresponding country $(0.39033$ frequency, 84 single country publication (SCP) followed by Iran (116), 858 citations, and 0.1487 frequency ( $33 \mathrm{SCP}$ ) as a contributing country on the subject (Table 4). South Korea is the third productive country (56) and cited country (632) corresponding authors' country $(0.09665,12 \mathrm{SCP})$. China is the fourth productive country (47), citation (471), and SCP (12). We found that Malaysia was the fifth productive (29), citations (346) but the fifth corresponding country is Egypt (0.02974, SCP of 5) and Malaysia is the sixth on the list for the authors' country. Concerning productivity, Asian countries were dominant in the research understudy (India, Iran, South Korea, China, Malaysia, Saudi Arabia, Thailand, Pakistan, Vietnam, Bangladesh, Iraq, Indonesia) with 3 African countries (Egypt, Nigeria and South Africa) and 2 North American countries (Mexico and USA), 2 South America (Argentina and Brazil). The productivity of the region countries could be ascribed to the fact that most of the research institutions are from Asian countries and most of the research funding agencies recorded in this study originated from these territories (Supplementary S6). Of which, the top 5 funding agencies include University Grants Commission India, Department of Science Technology India, Dean-

Table 4. Country productivity and corresponding author's country.

\begin{tabular}{|c|c|c|c|c|c|c|c|c|c|c|}
\hline \multicolumn{2}{|c|}{ Country productivity } & \multicolumn{3}{|c|}{ Most cited countries } & \multicolumn{6}{|c|}{ Corresponding author's country } \\
\hline Country & Frequency & Country & TC & AAC & Country & Articles & Freq & SCP & MCP & MCP_Ratio \\
\hline India & 270 & India & 3468 & 333,03 & India & 5 & 0,39033 & 84 & 21 & 0,2 \\
\hline Iran & 116 & Iran & 858 & 21,45 & Iran & 40 & 0,1487 & 33 & 7 & 0,175 \\
\hline South Korea & 56 & Korea & 632 & 24,31 & Korea & 26 & 0,09665 & 12 & 14 & 0,538 \\
\hline China & 47 & China & 471 & 26,17 & China & 18 & 0,06691 & 12 & 6 & 0,333 \\
\hline Malaysia & 29 & Malaysia & 346 & 43,25 & Egypt & 8 & 0,02974 & 5 & 3 & 0,375 \\
\hline Saudi Arabia & 28 & Egypt & 227 & 28,38 & Malaysia & 8 & 0,02974 & 2 & 6 & 0,75 \\
\hline Thailand & 17 & Saudi Arabia & 224 & 28,00 & Saudi Arabia & 8 & 0,02974 & 4 & 4 & 0,5 \\
\hline Egypt & 16 & USA & 199 & 49,75 & Thailand & 6 & 0,0223 & 5 & 1 & 0,167 \\
\hline Pakistan & 15 & Italy & 136 & 136,00 & Mexico & 5 & 0,01859 & 5 & 0 & 0 \\
\hline USA & 14 & Thailand & 106 & 17,67 & Turkey & 4 & 0,01487 & 4 & 0 & 0 \\
\hline Nigeria & 13 & Brazil & 65 & 21,67 & USA & 4 & 0,01487 & 3 & 1 & 0,25 \\
\hline Vietnam & 13 & Nigeria & 47 & 23,50 & Brazil & 3 & 0,01115 & 2 & 1 & 0,333 \\
\hline Bangladesh & 8 & Mexico & 35 & 7,00 & Indonesia & 3 & 0,01115 & 2 & 1 & 0,333 \\
\hline Iraq & 8 & Vietnam & 33 & 11,00 & Iraq & 3 & 0,01115 & 3 & 0 & 0 \\
\hline South Africa & 8 & Turkey & 32 & 8,00 & South Africa & 3 & 0,01115 & 3 & 0 & 0 \\
\hline Argentina & 7 & Poland & 26 & 13,00 & Vietnam & 3 & 0,01115 & 3 & 0 & 0 \\
\hline Brazil & 7 & South Africa & 20 & 6,67 & Argentina & 2 & 0,00743 & 2 & 0 & 0 \\
\hline Turkey & 7 & Japan & 18 & 9,00 & Japan & 2 & 0,00743 & 0 & 2 & 1 \\
\hline Indonesia & 6 & Argentina & 17 & 8,50 & Nigeria & 2 & 0,00743 & 1 & 1 & 0,5 \\
\hline
\end{tabular}

Freq - frequency, SCP - single country publications, MCP - multiple country publications 
ship of Scientific Research at King Saud University, National Natural Science Foundation of China and Scientific Industrial Research CSIR India. From our findings, we could observe that Asian countries were more committed to funding research in this research understudy than other continents, and this accounts for the reason why most of the corresponding authors are from Asia. One of the most influential factors that drive research is funding. Besides, a country that value the importance of research will support it because sophisticated laboratory instruments and reagents are very expensive. The absence of funding hinders research progress and discourage researchers. However, the availability of funding on the subject assisted the researchers in Asia as compared to other developing countries in Africa where research funding is lacking and the researchers tend to use their personal money to purchase equipment and reagents to carry out research. As a result, researchers' potentials or skills are hampered and consequently affects the quality of research output.

\section{Three-Fields plot (Keywords connection with authors and institutions)}

Keywords are important strategy for searching published documents in the literature (79). It is the cornerstones of the discoverability of any manuscript and therefore, quality journals and publishers should mandate the inclusion of keywords in every publication to ensure maximum visibility of the publication across all databases (68). A research hotspot refers to a focus of research for which scholars have explored severally for publication. By computing, the frequencies and relationships of words reflecting the content of articles that appear in a field, the hotspots of the field can usually be identified (80). Keywords are the essence of academic papers (81), through the analysis of high - frequency keywords (40), the overall characteristics and development trends of the field can be revealed (13), and research hotspots in this field are able to be obtained more efficiently (82).

It is highly important that researchers familiarize themselves with some specific terms used in a particular field they are interested in if not, searching for valuable documents will be difficult (83). Keywords are the keystones of the discoverability of any paper and hence, reputable publishers and journals should make compulsory the use of at least 5 keywords in a manuscript submission (84). The presence of keywords in an article increases the visibility and reflectiveness of the article across all databases (68). However, keywords were not mandatorily for articles published before 1995 and the visibility of those articles are very poor. During manuscript submission, because authors are obliged to fill the keywords section on the journal's website whereas the keywords might not be part of the original manuscript being submitted. Consequently, this irregularity hampered keyword analysis when searching for such published articles (85).

Author keywords could identify the central emphasis of a research article and pinpoint a certain pattern of the research based on analysing the most frequent keywords. The bibliometric analysis through author keywords has been proved to be an effective method in revealing the sci- entific research trends and hotspots (39). The most frequently used keywords in the field are represented in Fig 4a. In the same vein, Fig. 4a reveals the connection between the most frequently used keywords in this subject with key authors and most productive countries. We observed that Indian researchers have exploited most of the keywords in their published papers on the subject followed by Iran and Korea. Similarly, the 20 topmost occurrence terms in all the articles on the subject are regarded as the present research hotspots in the field. For example, the word "biosynthesis" was recorded 108 times, "leaf extract" was 68 times, "extract" appeared 42 times and "antimicrobial" was recorded 37 times (Supplementary Fig. S2).

\section{Co-citations network}

The results of the co-citation network of the top 22 authors related to the subject study are represented in Fig. 5. Each node in the sphere grid indicates different authors and the diameter of the node relates to the cocitation rate with other researchers in the field, and lines illustrate the co-citation network among the authors. The age of a paper influences its citation over the year. From this study, we observed that Sharma VK, Morones Jr, Shankar SS, Krishnaraj C and Sondi were the top 5 with a high co-citation rate and these authors interconnect with themselves (Fig. 5). Papers published 10 years ago will have more citations more than those published a year ago (86). This accounts for why recently published papers do not appear in the results presented in this section (Fig. 5). Most other similar analyses have been used for bibliometric analysis by several researchers in different studies $(53,66)$.

\section{co-occurrence of keywords and trend topics over the years}

Supplementary Fig. S2 reveals the co-occurrence of keywords on the subject study. The most frequent words used was biosynthesis and it was recorded 108 in the study, followed by leaf extract (68), extract (42), antimicrobial activity (37), reduction (31 times), Escherichia coli (29), Ag (25), antioxidant (24), metal nanoparticles (24), particles (19), ions (16), leaves (16), size (16), optical properties (15), plant (15), bacteria (13), toxicity (13). In addition, Fig. 6 depicts trend topics on the subject study over the years. To understand the green synthesis of metallic nanoparticles, some topics have been chosen as the focus of active research in the field. Between 2014 and 2016, the trend topics were growth, plant, toxicity, rapid synthesis, model, gold, Escherichia coli, Ag, particles, au and ions. Subsequently, between 2016 to 2020, the hotspot topics for research were biosynthesis, leaf extract, gold nanoparticles, extract, antimicrobial activity, reduction, metal nanoparticles, antioxidant, leaves, cytotoxicity, degradation, anticancer, 4nitrophenol, oxide nanoparticles and mechanism. The rate at which the word "biosynthesis" was frequently used in 2017 followed by leaf extract. Recently, researchers in this field have diverted their attention to areas such as cytotoxicity, degradation, anticancer and their possible mechanisms of action. Potential applications of metal nanoparticles especially silver and gold nanoparticles such as catalyt- 
ic, biomedical, bioremediation of green metallic nanoparti- quality and resources and this has been encouraged by cles have been extensively reported in the literature (87, most funding agencies because research individualism 88).

hampers progress and quality outputs $(45,89)$.

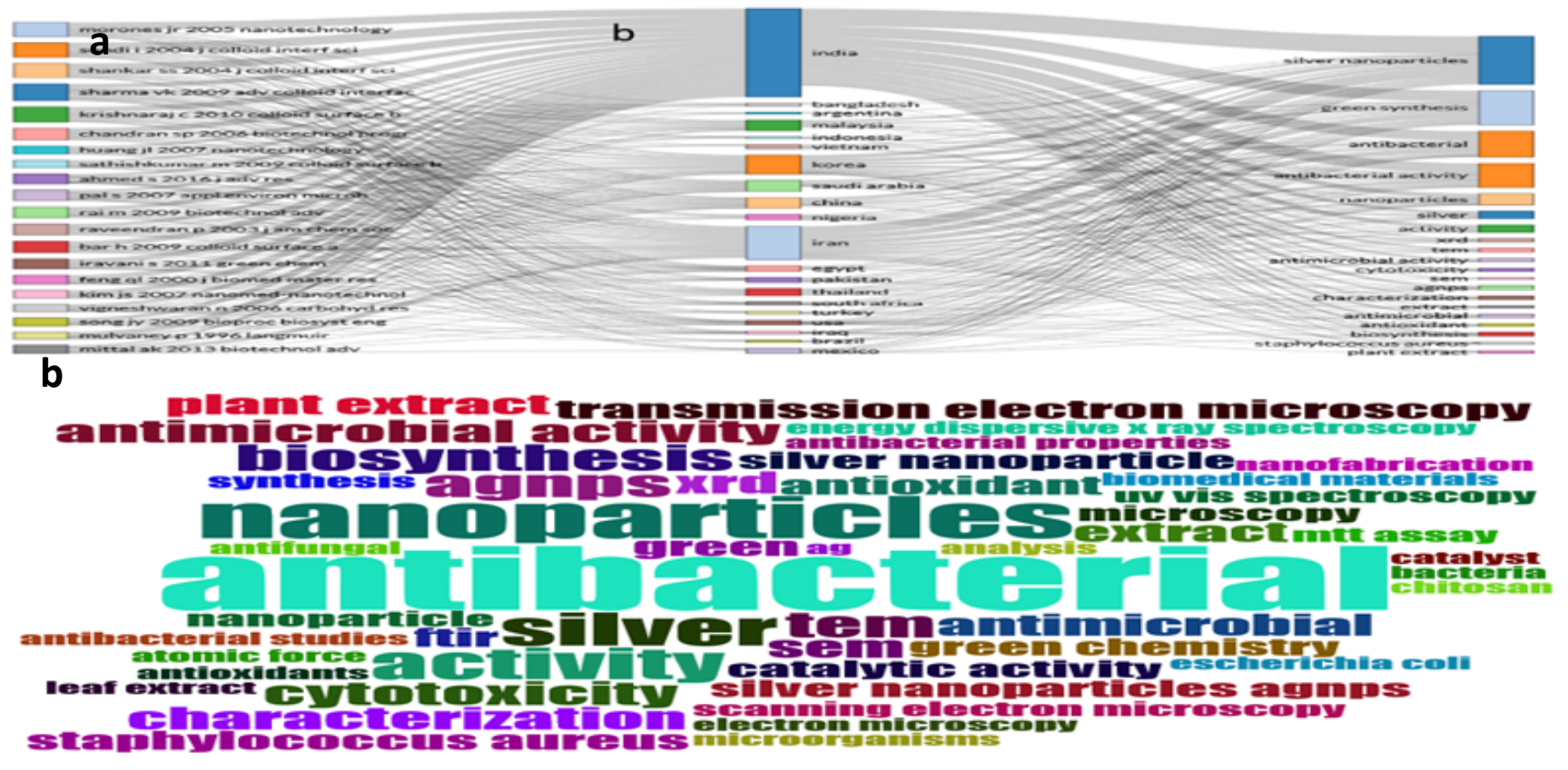

Fig. 4. Keywords connection with authors and institutions (a) and frequent words (b) used on antibacterial activity of green silver nanoparticles.

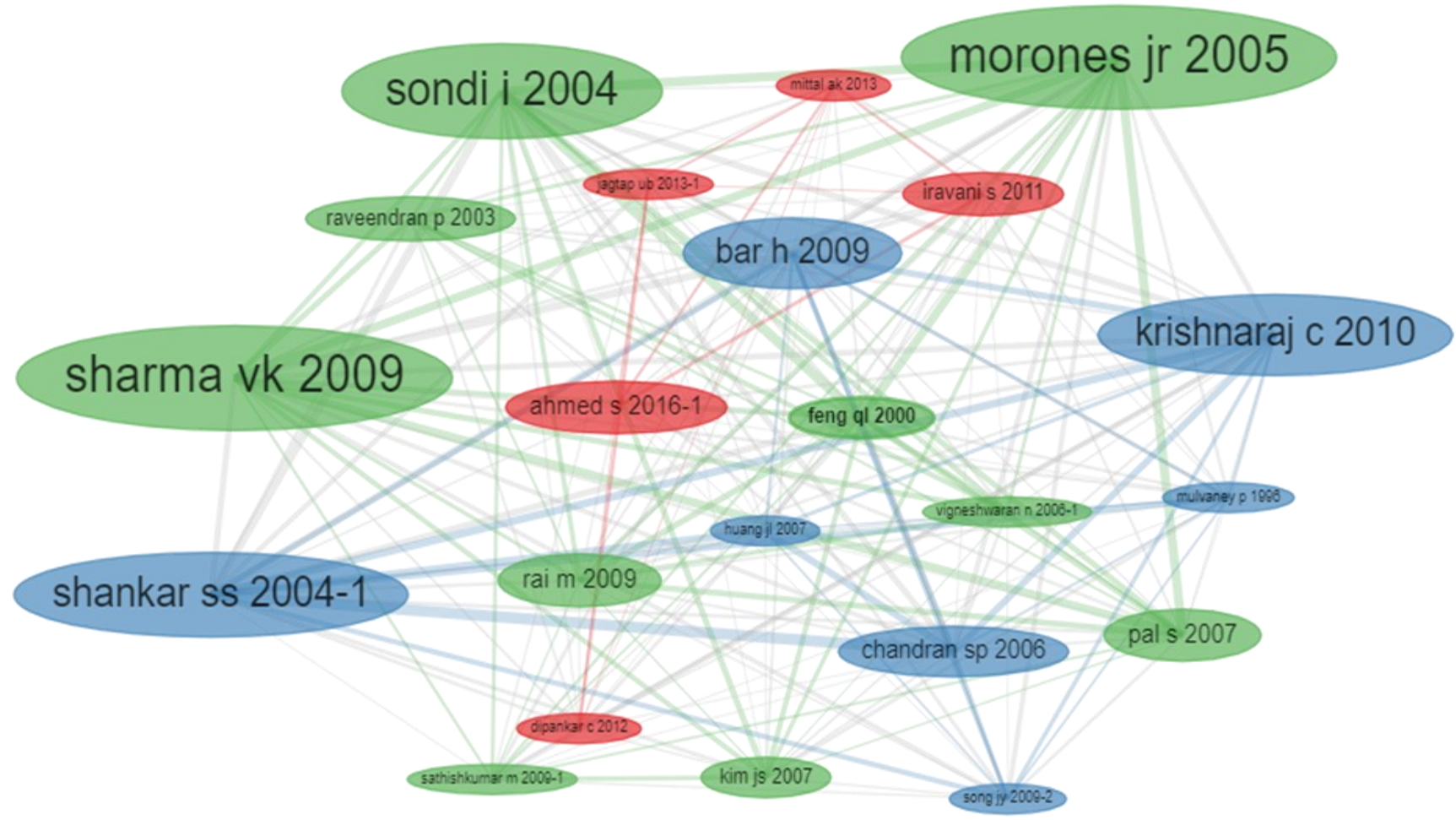

Fig. 5. Co-citation network on antibacterial activity of green silver nanoparticles.

\section{Authors, institutions and countries collaboration network}

This section displays the collaboration network among the researchers in the field study. From the results represented in Fig. 7a, we observed a strong research collaboration network between some authors and this initiative increased their research outputs significantly such that it accounted for the productivity of their respective institutions and countries. Research collaboration improves productivity,
The analysis of institutional collaboration networks on the subject is depicted in Fig 7b. We observed that some institutions have a collaboration network with each other whereas some do not involve in international collaboration and this critical factor adversely affected research productivity. As seen in Fig 7b, some institutions have a powerful network involving three (3) parties whereas others involved 2 parties. Research collaboration among scholars enhances the exchange of skills, experience, resources, knowledge, 


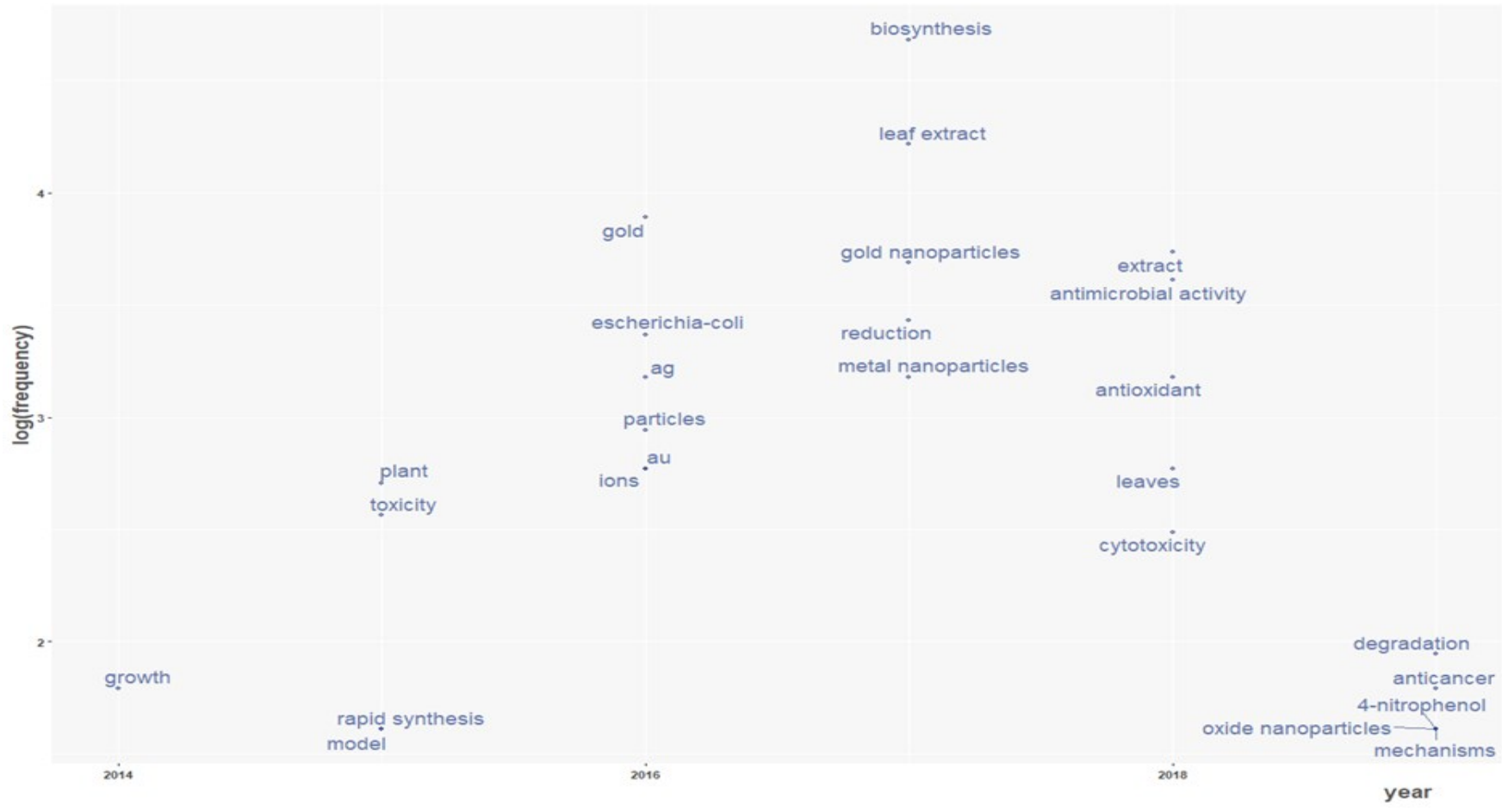

Fig. 6. Trend topics on antibacterial activity of green silver nanoparticles.
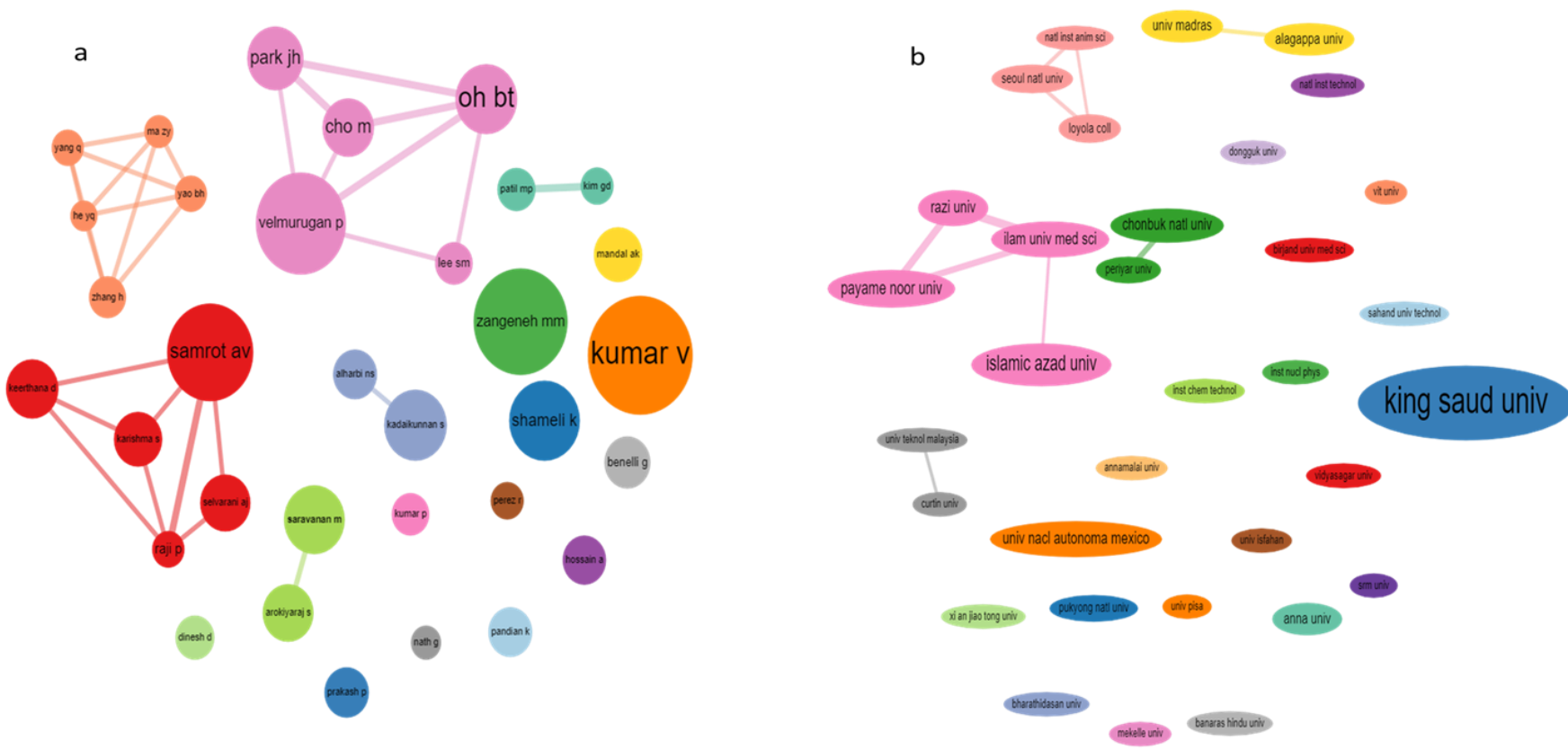

Fig. 7. Authors (a) and institutions (b) collaboration networks on antibacterial activity of green silver nanoparticles.

techniques and impactful ideas among the participants. An top of every research. However, the low research outputs increase in research collaboration increases the possibili- observed in specific countries could be due to a lack of colties of problem-solving. An additional advantage of working laboration networks on the subject as seen in Fig 8 . Iran has in partnership with research scholars outside your institu- a collaboration network with Malaysia, Iran, Iraq and Indotion is the prospect to grow as an intellectual author and nesia. Japan has a network with Bangladesh whereas other this will enable you to think differently contrary to when countries such as Hungary, Singapore, Brazil, Poland, Zimyou are working only with your colleagues with a similar babwe, China, New Zealand, Poland, Vietnam, Turkey, Norline of thinking $(45,46)$.

As represented in Fig. 8, we observed that India has a research collaboration network with Russia, Ethiopia, Saudi Arabia, United Arab Emirates, Korea, South Africa, Italy, USA and Malaysia. It is very strange to see that USA and China are not at the top of the list because they are the strongest research competitors and they are always at the way, Jordan, Thailand, Belarus, Nigeria, Australia, Argentina, Denmark, Canada, United Kingdom, Taiwan, Ireland and Portugal do not have a research collaboration network with any country in the field and these accounts for the low productivity in these regions. The high research outputs on the subject from India and Iran could be due to the high number of corresponding authors from these territories. As highlighted by the report of Okaiyeto and Oguntibeju (45), 
Country Collaboration Map

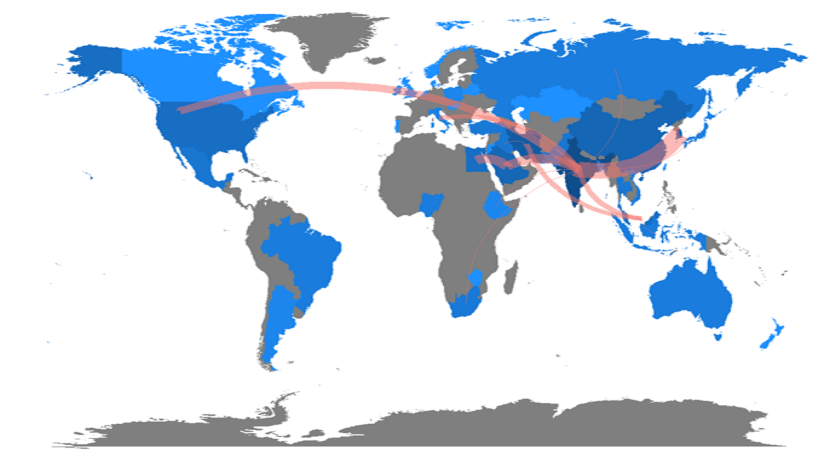

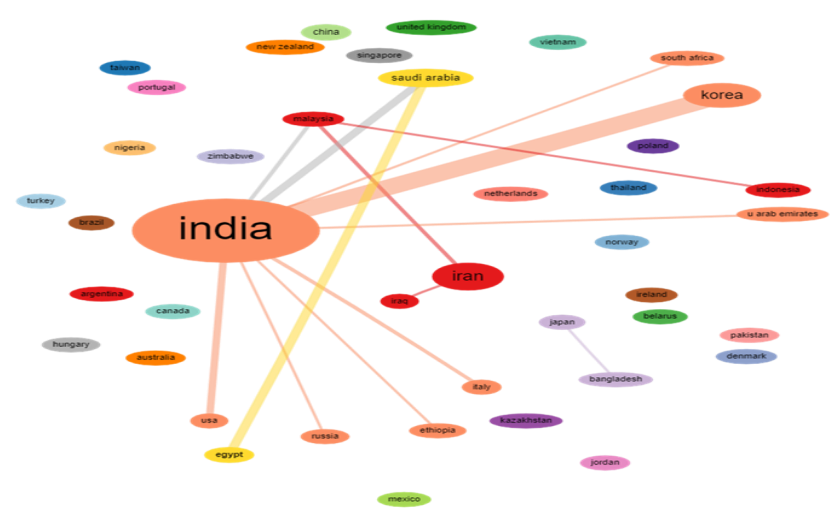

Fig. 8. Countries collaboration network on antibacterial activity of green silver nanoparticles.

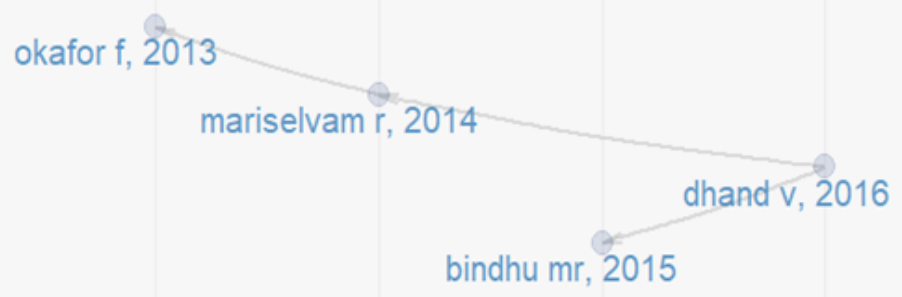

shameli k, 2012

zargar $m, 2011$

kora aj, 2010

ghaffari-moghaddam m, 2014

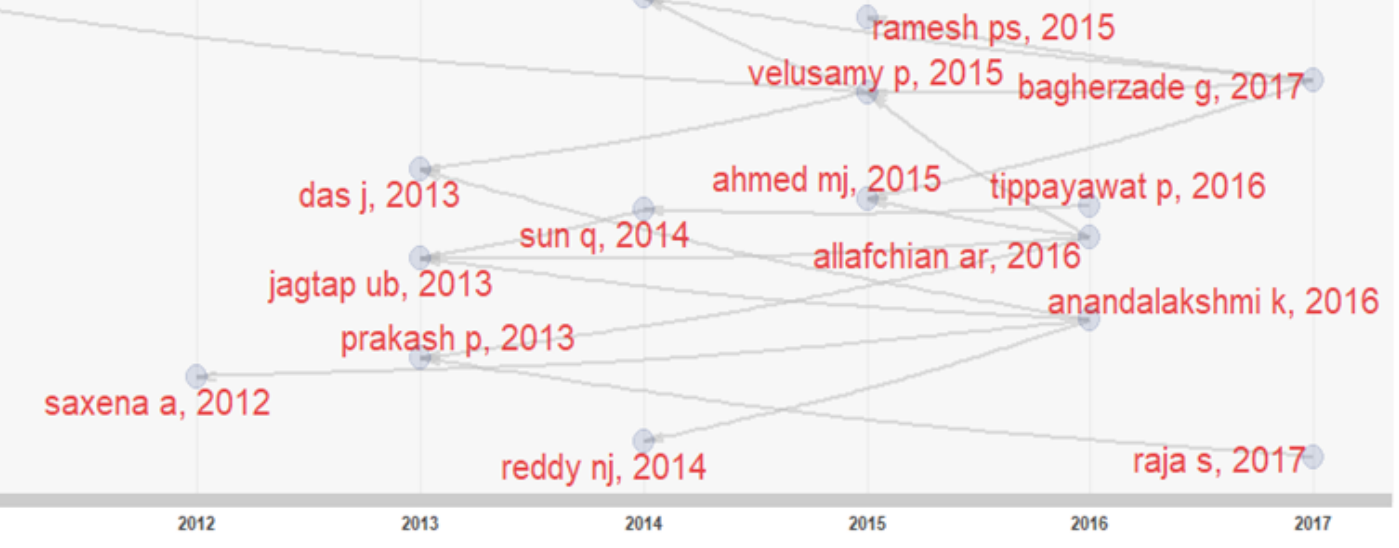

Fig. 9. Historical direct citation network on antibacterial activity of green silver nanoparticles.

international collaborations between countries provide prospects for the exchange of skills and ideas for new discoveries, division of labour and resources, key strategies to solve significant logical questions in a particular field.

\section{Historical direct citation network}

A historical direct citation network that deploys a chronological citation network is presented as an intellectual structure (Fig. 9). As highlighted in one report (90), it denotes a chronological map of the most significant citations subsequent from a bibliographic collection. The remarkable part of this visualization is that apart from revealing the authors' names and connections over the years, it also highlights some relevant topics on the subject, which could be useful for research scholars in the field.

\section{Conclusion and limitations}

The present bibliometric analyses revealed the global research trends on antibacterial activity of green silver nanoparticles between 2000 and 2020 which is based on the re- trieved research articles from SCl-Expanded. Concerning the various analyses performed in this study, the method used to extract data from the literature and software used for analysis in this study is widely accepted. Our analyses showed that there is research progress in the field over the year and we noticed that research collaboration greatly increased productivity among the authors, institutions and countries and low research outputs among those collaborative networks. This study further identifies the impact of research funding on productivity and we hope that researchers in the field from institutions and countries with low productivity would be encouraged about the essence of research collaboration in their future studies.

Furthermore, in the present study, we identified a few limitations that might affect our bibliometric analyses in one way or the other. For example, in our search, we only consider research articles published in English, and those published in other languages are excluded in this analysis. Similarly, those published in databases other than SClExpanded were also excluded from the search as well as 
those published documents that are not research articles. Furthermore, we used the WoS database to retrieve research articles included in the bibliometric analysis without consulting other scientific databases. Although, WoS have been acknowledged to be one of the oldest databases to retrieve information for this kind of analysis, nonetheless, the data obtained from WoS cannot holistically represent all research data on the subject study because some journals are not indexed in the WoS but indexed in other scientific databases such as Scopus, PubMed, etc. Hence, we can say that our opinion is only based on the information in WoS (SCl-Expanded) and articles.

\section{Acknowledgements}

Authors would like to thank Cape Peninsula University of 7 Technology for technical and financial support for this study.

\section{Authors contributions}

Conceptualization, $\mathrm{KO}$ and OOO; resources, 000; writing - 9. original draft preparation, $\mathrm{KO}$; writing - review and editing, KO, 100 and OOO; supervision -000; project administration, 000; funding acquisition, 000. All the authors have read and agreed to the published version of the manuscript.

\section{Compliance with ethical standards}

Conflict of interest: Authors do not have any conflict of interests to declare.

Ethical issues: None.

\section{Supplementary data}

Table S1: Top 20 most impactful authors.

Table S2: Author productivity through Lotka Law.

Table S3: Author's production over time (2000 - 2020).

Table S4: Top 20 Web of Science categories of published on antibacterial activity of green silver nanoparticles.

Table S5: Bradford's Law.

Table S6: Funding agencies.

Figure S1: 20 most local cited authors.

Figure S2: Co-occurrence words used in the field.

\section{References}

1. Gopinath K, Kumaraguru S, Bhakyaraj K, Mohan S, Venkatesh KS, Esakkirajan M, Kaleeswarran P, Alharbi NS, Kadaikunnan S, Govindarajan MG, Benelli A, Arumugam. Green synthesis of silver, gold and silver/gold bimetallic nanoparticles using the Gloriosa superba leaf extract and their antibacterial and antibiofilm activities, Microb Pathog. 2016;101:1-11.

2. Okaiyeto K, Ojemaye MO, Hoppe H, Mabinya LV, Okoh Al. Phytofabrication of silver/silver chloride nanoparticles using aqueous leaf extract of Oedera genistifolia: Characterization and antibacterial potential. Molecules. 2019;244:382. https:// doi.org/10.3390/molecules24234382

3. Adeyemi JO, Elemike EE, Onwudiwe DC, Singh M. Bio-inspired synthesis and cytotoxic evaluation of silver-gold bi-metallic nanoparticles using Kei-Apple (Dovyalis caffra) fruits. Inorganic Chemistry Communications. 2019;109:107569.

4. Agarwal H, Kumar SV, Rajeshkumar S. A review on green synthesis of zinc oxide nanoparticles-an eco-friendly approach," Resource-Efficient Technologies. 2017;3:406-13.

5. Kalpana VN, Rajeswari VD. Review on green synthesis, biomedical applications, and toxicity studies of ZnO NPs. Bio-inorganic Chemistry and Applications. 2018;Article ID 3569758, 12 pages https://doi.org/10.1155/2018/3569758.

6. Jeevanandam J, Barhoum A, Chan YS, Dufresne A, Danquah MK. Review on nanoparticles and nanostructured materials: history, sources, toxicity and regulations. Beilstein J Nanotechnol. 2018;9:1050-74. https://doi.org/10.3762/bjnano.9.98.

Teulon JM, Godon C, Chantalat L, Moriscot C, Cambedouzou J, Odorico M. et al. On the Operational Aspects of Measuring Nanoparticle Sizes. Nanomater. 2019;9:18. https://doi.org/10.3390/ nano9010018.

8. Geethalakshmi R, Sarada DV. Gold and silver nanoparticles from Trianthema decandra: synthesis, characterization, and antimicrobial properties, Int J Nanomed. 2012;7:5375-84.

Jamkhande PG, Ghule NW, Bamer AH, Kalaskar MG. Metal nanoparticles synthesis: An overview on methods of preparation, advantages and disadvantages and applications. Journal of Drug Delivery Science and Technology. 2019;53:101174.

10. Pourmortazavi SM, Taghdiri M, Makari V, Rahimi-Nasrabadi M. Procedure optimization for green synthesis of silver nanoparticles by aqueous extract of Eucalyptus oleosa. Spectrochimica Acta Part A: Molecular and Biomolecular Spectroscopy. 2015;136:1249-54

11. Chitsazi MR, Korbekandi H, Asghari G, Bahri Najafi R, Badii A, Iravani S. Synthesis of silver nanoparticles using methanol and dichloromethane extracts of Pulicaria gnaphalodes (Vent.) Boiss. aerial parts. Artifl cells, Nanomed Biotechnol. 2016;44:328-33.

12. Sre PR, Reka M, Poovazhagi R, Kumar MA, Murugesan K. Antibacterial and cytotoxic effect of biologically synthesized silver nanoparticles using aqueous root extract of Erythrina indica Lam. Spectrochimica Acta Part A: Molecular and Biomolecular Spectroscopy. 2015;135:1137-44.

13. Mohanta YK, Biswas K, Jena SK, Hashem A, Abd Allah EF, Mohanta TK. Anti-biofilm and antibacterial activities of silver nanoparticles synthesized by the reducing activity of phytoconstituents present in the Indian medicinal plants. Frontiers in Microbiology. 2020;11:1143.

14. Gupta R, Xie H. Nanoparticles in daily life: applications, toxicity and regulations. J Environ Pathol Toxicol Oncol. 2018;37:209-30. https://10.1615/JEnvironPatholToxicolOncol.2018026009

15. Zhang Y, Yao X, Qin B. A critical review of the development, current hotspots, future directions of Lake Taihu research from the bibliometrics perspective. Environ Sci Pollut Res. 2016;23:1281121. https://doi.org/10.1007/s11356-016-6856-1.

16. De Almeida TM, Pal K, de Souza FG. Bibliometric analysis of the hot theme phytosynthesized nanoparticles. Arch Biomed Eng Biotechnol. 2020;4:ABEB.MS.ID.000580. https://doi.org/10.33552/ ABEB.2020.04.000580.

17. Arya G, Kumari RM, Sharma N, Chatterjee S, Gupta N, Kumar A, Nimesh S. Evaluation of antibiofilm and catalytic activity of biogenic silver nanoparticles synthesized from Acacia nilotica leaf extract. Adv Nat Sci Nanosci Nanotechnol. 2018;9:045003.

18. Luo Z, Zhang L, Zeng R, Su L, Tang D. Near-infrared light-excited core-core-shell UCNP@Au@CdS up conversion nanospheres for ultrasensitive photoelectrochemical enzyme immunoassay. Anal Chem. 2018;90:9568-75.

19. Qiu Z, Shu J, Liu J, Tang D. Dual-channel photoelectrochemical 
ratiometric ap-tasensor with up-converting nanocrystals using spatial-resolved technique on homemade 3D printed device. Anal Chem. 2019;91:1260-68.

20. Markus J, Wang D, Kim YJ, Ahn S, Mathiyalagan R, Wang C, Yang DC. Biosynthesis, characterization and bioactivities evaluation of silver and gold nanoparticles mediated by the roots of Chinese herbal Angelica pubescens Maxim, Nanoscale Res Lett. 2017;12:46.

21. Mousavi SM, Hashemi SA, Ghasemi Y. Green synthesis of silver nanoparticles toward bio and medical applications: review study. Artif Cells 2018;46(sup 3):855-72.

22. Khan I, Saeed K, Khan I. Nanoparticles: properties, applications and toxicities, Arab J Chem. 2017. https://doi.org/10.1016/ j.arabjc.2017.05.011.

23. Mussin J, Robles-Botero V, Casañas-Pimentel R, Rojas F, Angiolella L, San Martín-Martínez E, Giusiano G. Antimicrobial and cytotoxic activity of green synthesis silver nanoparticles targeting skin and soft tissue infectious agents. Scientific Reports. 2021;11(1):1-12.

24. Bastian M, Heymann S, Jacomy M. Gephi: An open source software for exploring and manipulating networks. Third International AAAI Conference on Weblogs and Social Media. 2009; https://doi. org/10.1136/qshc.2004.01003 3.

25. Piccinno F, Gottschalk F, Seeger S, Nowack B. Industrial production quantities and uses of ten engineered nanomaterials in Europe and the world. Journal of Nanoparticle Research 2012;14 (9):https://doi.org/10.1007/s1105 1-012-1109-9.pone.0207655.

26. León-Silva S, Fernández-Luqueño F, López-Valdez, F. Silver nanoparticles (AgNP) in the environment: A review of potential risks on human and environmental health. Water, Air and Soil Pollution. 2016;227(9):306.https://doi.org/10.1007/s1127 0-016-3022-9.

27. León-Silva S, Fernández-Luqueño F, Záyago-Lau E, López-Valdez F. Silver nanoparticles, research and development in Mexico: A bibliometric analysis. Scientometrics. 2020;123:31-49. https:// doi.org/10.1007/s11192-020-03367-y

28. Ahmed MJ, Murtaza G, Mehmood A, Bhatti TM. Green synthesis of silver nanoparticles using leaves extract of Skimmia laureola: Characterization and antibacterial activity. Materials Letters 2015;153:10-13.

29. Rodríguez-León E, Îñiguez-Palomares RA, Navarro RE, RodríguezBeas C, Larios-Rodríguez E, Alvarez-Cirerol FJ, Íñiguez-Palomares C, Ramírez-Saldaña M, Martínez JH, Martínez-Higuera A, GalvánMoroyoqui JM, Martínez-Soto JM. Silver nanoparticles synthesized with Rumex hymenosepalus extracts: effective broadspectrum microbicidal agents and cytotoxicity study, Artificial Cells, Nanomedicine and Biotechnology. 2018;46:1194-1206. https://doi.org/10.1080/21691401.2017.1366332.

30. Abdullah AA, Mohammed A, AlAkeel R, Abdulaziz A. Biogenic silver nanoparticles by Myrtus communis plant extract: biosynthesis, characterization and antibacterial activity. Biotechnology and Biotechnological Equipment. 2019;33:931-36. https:// doi.org/10.1080/13102818.2019.1629840

31. Ravichandran V, Vasanthi S, Shalini S, Shah SAA, Tripathy M, Paliwal N. Green synthesis, characterization, antibacterial, antioxidant and photocatalytic activity of Parkia speciosa leaves extract mediated silver nanoparticles. Results in Physics. 2019;15:102565.

32. Kumar V, Singh S, Srivastava B, Bhadouria R, Singh R. Green synthesis of silver nanoparticles using leaf extract of Holoptelea integrifolia and preliminary investigation of its antioxidant, antiinflammatory, antidiabetic and antibacterial activities. Journal of Environmental Chemical Engineering. 2019;7:103094.

33. Okaiyeto, K., Ojemaye, M.O., Hoppe, H., Mabinya, L.V. and Okoh, A.I., 2019. Phytofabrication of silver/silver chloride nanoparticles using aqueous leaf extract of Oedera genistifolia: Characterization and antibacterial potential. Molecules. 24(23):4382.
34. Raota CS, Cerbaro AF, Salvador M, Delamare APL, Echeverrigaray S, Crespo JS, da Silva TB, Giovanela M. Green synthesis of silver nanoparticles using an extract of Ives cultivar (Vitis labrusca) pomace: Characterization and application in wastewater disinfection. Journal of Environmental Chemical Engineering. 2019;7:103383

35. Ahmad MA, Salmiati S, Marpongahtun M, Salim MR, Lolo JA, SA. Green synthesis of silver nanoparticles using Muntingia calabura leaf extract and evaluation of antibacterial activities. 2020;10:6253-61. https://doi.org/10.33263/BRIAC105.62536261.

36. Ahmad P, Dummer P, Noorani T, Asif J. The top 50 most-cited articles published in the International Endodontic Journal Int Endod J. 2019;52:803-18.

37. Fu HZ, Wang MH, Ho YS. Mapping of drinking water research: a bibliometric analysis of research output during 1992-2011 Sci Total Environ. 2013;443:757-65.

38. Ruhanen L, Weiler B, Moyle BD, McLennan CLJ. Trends and patterns in sustainable tourism research: A 25-year bibliometric analysis. J Sust Tour. 2015;23:517-35.

39. Ding $\mathrm{Y}$, Chen D, Ding X, Wang G, Wan Y, Shen Q. A bibliometric analysis of income and cardiovascular disease: Status, hotspots, trends and outlook. Medicine. 2020;99(34).

40. Su H, Lee P. Mapping knowledge structure by keyword cooccurrence: A first look at journal papers in Technology Foresight. Scientometrics. 2010;85:65-79.

41. Corte VD, Gaudio GD, Sepe F, Sciarelli F. Sustainable tourism in the open innovation realm: A bibliometric analysis. Sustainability. 2019;11:6114. https://doi.org/10.3390/su11216114

42. Kadic AJ, Kovacevic T, Runjic E, Majce AS, Markic J, Polic B, Mestrovic J, Puljak L. Research methodology used in the 50 most cited articles in the field of pediatrics: types of studies that become citation classics. BMC Medical Research Methodology. 2020;20:1-9.

43. Nwagwu WE. A bibliometric analysis of productivity patterns of biomedical authors of Nigeria during 1967-2002. Scientometrics. 2006;9:259-69.

44. Okaiyeto K, Ekundayo TC, Okoh Al. Global research trends on bioflocculant potentials in wastewater remediation from 1990 to 2019 using a bibliometric approach. Letters in Applied Microbiology. 2020;71(6):567-79.

45. Okaiyeto $\mathrm{K}$, Oguntibeju OO. Trends in diabetes research outputs in South Africa over 30 years from 2010-2019: A bibliometric analysis. Saudi Journal of Biological Sciences. 2021;28 (5):2914-24.

46. Okaiyeto K, Oguntibeju OO. A Web of Science-based Analysis of Global Research Trends on Moringa oleifera from 2010-2019. Journal of Natural Remedies. 2021;21(4):333-49.

47. Gray Neils ME, Pfaeffle HO, Kulatti AT, Titova A, Lyles GS, Plotnikova $Y$, Zorkaltseva E, Ogarkov OB, Vitko SM, Dillingham RA, Heysell SK. A Geospatial Bibliometric Review of the HIV/AIDS Epidemic in the Russian Federation. Frontiers in public health. 2020;8:75.

48. Sweileh WM, Al-Jabi SW, Sawalha AF, AbuTaha AS, Zyoud SEH. Bibliometric analysis of worldwide publications on antimalarial drug resistance (2006-2015). Malaria Research and Treatment. 2017.

49. Wu CC, Wang YZ, Hu HY, Wang XQ. Bibliometric analysis of research on the comorbidity of cancer and pain. Journal of Pain Research. 2021;14:213.

50. Zyoud SH, Waring WS, Al-Jabi SW, Sweileh WM. Global cocaine intoxication research trends during 1975-2015: A bibliometric analysis of Web of Science publications. Subst Abus Treat Prev Policy. 2017. https://doi.org/10.1186/s13011-017-0090-9

51. Harzing AW, Alakangas S. Google Scholar, Scopus and the Web of Science: A longitudinal and cross-disciplinary comparison. Scientometrics. 2016;106:787-804. 
52. Ho YS. Rebuttal to: Su et al. The neurotoxicity of nanoparticles: A bibliometric analysis. Vol. 34:922-29. Toxicol and Industrial Health. 2019;35:399-402.

53. Olisah C, Okoh OO, Okoh Al. Global evolution of organochlorine pesticides research in biological and environmental matrices from 1992 to 2018: A bibliometric approach. Emerging Contaminants. 2019;5:157-67.

54. Ho YS (2018a). Comments on "Mapping the scientific research on non-point source pollution: A bibliometric analysis" by Yang et al. Environ Sci and Pollut Res. 2017;25(30):30737-38.

55. Ho YS. Comment on: "A bibliometric analysis and visualization of medical big data research" Sustainability 2018, 10, 166. Sustainability 2018b;10:4851.

56. Jafarzadeh H, Sarraf Shirazi A, Andersson L. The most-cited articles in dental, oral and maxillofacial traumatology for 64 years. Dent Traumatol. 2015;31:350-60.

57. Zheng TL, Wang J, Wang QH, Meng HM, Wang LH. Research trends in electrochemical technology for water and wastewater treatment. Appl Water Sci. 2017;7:13-30.

58. Jaffe K, ter Horst E, Gunn LH, Zambrano JD, Molina G. A network analysis of research productivity by country, discipline and wealth. PLoS One. 2020;15(5):1-15.

59. Heng K, Hamid MO, Khan A. Factors influencing academics' research engagement and productivity: A developing countries perspective. Issues in Educational Research. 2020;30(3): 965-87.

60. Tarazona-Alvarez B, Lucas-Dominguez R, Paredes-Gallardo V, Alonso-Arroyo A, Vidal-Infer A. A bibliometric analysis of scientific production in the field of lingual orthodontics. Head and Face Medicine. 2019;15(1): 1-10.

61. Qi Y, Chen X, Hu Z, Song C, Cui Y. Bibliometric analysis of algalbacterial symbiosis in wastewater treatment. Int J Environ Res Public Health. 2019;16:1077.

62. Uthman OA, Uthman MB. "Geography of Africa biomedical publications: an analysis of 1996-2005 PubMed papers", In-ternational Journal of Health Geographics. 2007;6:1-11.

63. Adigwe I. Lotka's Law and productivity patterns of authors in biomedical science in Nigeria on HIV/AIDS: A bibliometric approach. The Electronic Library. 2016;34:789-807.

64. Ruiz-Castillo J, Costas R. "The skewness of scientific productivity", UC3M Working Papers, Departamento de Economía Economics Universidad Carlos III de Madrid 14-02, Calle, Madrid. 2014;156.

65. Fricke R, Uibel S, Klingelhoefer D, Groneberg DA. Influenza: A scientometric and density-equalizing analysis. BMC Infectious Diseases. 2013;13:454.

66. Orimoloye IR, Ololade 00. Global trends assessment of environmental health degradation studies from 1990 to 2018. Environment, Development and Sustainability. 2020. https:// doi.org/10.1007/s10668-020-00716-y

67. Kumar S, Duhan M, Haleem A. Evaluation of factors important to enhance productivity. Cogent Engineering. 2016;3:1145043.

68. Arshad Al, Ahmad P, Karobari MI, Asif JA, Alam MK, Mahmood Z, Abd Rahman N, Mamat N, Kamal MA. Antibiotics: A bibliometric analysis of top 100 classics. Antibiotics. 2020;9:219. https:// doi.org/10.3390/antibiotics9050219.

69. Hirsch JE. An index to quantify an individual's scientific research output. Proceedings of the National Academy of Sciences of the United States of America. 2005;102:16569-572.

70. Schreiber, M. An empirical investigation of the g-index for 26 physicists in comparison with the $\mathrm{h}$-index, the A-index and the Rindex. Journal of the American Society for Information Science and Technology. 2008;59:1513.

71. Nash-Stewart CE, Kruesi LM, Del Mar Chris B. Does Bradford's Law of Scattering predict the size of the literature in Cochrane Reviews? J Med Lib Assoc. 2012;100(2).
72. Bradford SC, Egan ME, Shera JH. Documentation. 2nd ed. London, UK: Crossby Lockwood;1953.

73. Hjørland B, Nicolaisen J. Bradford's Law of Scattering: ambiguities in the concept of "subject." In: Crestani F, Ruthven I, eds. Context: nature, impact and role: 5th International Conference on Conceptions of Library and Information Sciences Springer. 2005;96-106. (Lecture Notes in Computer Science, v.3507.)

74. Heine M. Bradford ranking conventions and their application to a growing literature. J Documentation. 1998;54(3):303-31.

75. Potter J. Mapping the literature of occupational therapy: an update. J Med Lib Assoc. 2010;98:235-42.

76. Aksnes, D.W. Citations and their use as indicators in science policy: Studies of validity and applicability issues with a particular focus on highly cited papers (Doctoral thesis). University of Twente, Enschede, The Netherlands, 2005.

77. Aksnes DW, Langfeldt L, Wouters P. Citations, Citation Indicators and Research Quality: An Overview of Basic Concepts and Theories. SAGE Open. 2019;1-17.

78. Feijoo JF, Limeres J, Fernández-Varela M, Ramos I, Diz P. The 100 most cited articles in dentistry. Clin. Oral Investig. 2014;16:699706.

79. Natarajan K, Stein D, Jain S, Elhadad N. An analysis of clinical queries in an electronic health record search utility. Int J Med Inform. 2010;79:515-22.

80. Chen HL, Zhao GQ, Xu NY. The analysis of research hotspots fronts of knowledge visualization based on CiteSpace II. In: Fong $\mathrm{J}$ (editor) Hybrid Learning: 5th International Conference, ICHL 2012, Guangzhou, China, August 13-15, 2012, Proceedings (Lecture Notes in Computer Science / Theoretical Computer Science and General Issues). Berlin: Springer; 2012;57-68.

81. Jones KS, Jackson DM. The use of automatically-obtained keyword classifications for information retrieval. Inf Storage Retrieval. 1970;5:175-201.

82. Wei Z, Ji G. Constructed wetlands, 1991-2011: A review of research development, current trends, and future directions. Sci Total Environ. 2012; 441:19-27.

83. Asghari S, Navimipour NJ. Nature inspired meta-heuristic algorithms for solving the service composition problem in the cloud environments. Int J Commun Syst. 2018; 31: e3708.

84. Okaiyeto $\mathrm{K}$, Oguntibeju OO. Evaluation of 100 most cited research articles on African medicinal plants. Plant Science Today. 2021; 8(2): 340-51.

85. Ling LL, Schneider T, Peoples AJ, Spoering AL, Engels I, Conlon BP, Mueller A, Schaeberle TF, Hughes DE, Epstein S et al. A new antibiotic kills pathogens without detectable resistance. Nature. 2015; 517:455-59.

86. Baek S, Yoon DY, Lim KJ, Cho YK, Seo YL, Yun EJ. The most downloaded and most cited articles in radiology journals: A comparative bibliometric analysis. Eur Radiol. 2018;28:4832-38.

87. Alharbi FA, Alarfaj AA. Green synthesis of silver nanoparticles from Neurada procumbens and its antibac-terial activity against multi-drug resistant microbial pathogens. Journal of King Saud University Science. 2020;32:1346-52.

88. Jiraporn C, Sineenat S. Light-mediated green synthesis of DNAcapped silver nanoparticles and their antibacterial activity. J Nanosci Nanotechnol. 2020;20:1678-84.

89. Krishna RAG, Espenti CS, Reddy YVR, Obbu A, Satyanarayan, MV. Green synthesis of silver nanoparticles by using Sansevieria roxburghiana, their characterization and antibacterial activity. J Inorg Organomet Polym Mater. 2020;30: 4155-59.

90. Borgman CL, Furner J. Scholarly communication and bibliometrics. Ann Rev Inf Sci Technol. 2002;36:2-72 